\title{
Revisión sistemática de estudios sobre inocuidad alimentaria en Cuenca, Ecuador, periodo 1981-2017
}

\author{
Johana Ortiz-Ulloa ${ }^{1}$, Michelle Castro 2 , Angélica Ochoa ${ }^{3}$ e Silvana Donoso ${ }^{4}$
}

\begin{abstract}
Objetivo: Evaluar la evidencia existente sobre inocuidad alimentaria en el cantón Cuenca, Ecuador. Materiales y métodos: Se realizó una revisión sistemática de los estudios en inocuidad alimentaria (microorganismos, contaminantes y adulterantes) durante el período 1981-2017. Resultados: Inicialmente se identificaron 640 estudios. Luego del análisis de los criterios de inclusión y exclusión, se incluyeron 40 estudios relacionados a evaluaciones microbiológicas (67.5\%), pesticidas, parásitos y antibióticos $(7.5 \%)$, conservantes y metales $(10 \%)$ y toxinas (15\%). Discusión: En los estudios se recalca la necesidad de implementar medidas de higiene y monitoreo, control en la manipulación, transporte y almacenamiento, control de los alimentos frescos cuya calidad no está regida por normativas nacionales, capacitar a los manipuladores y vendedores ambulantes. Esta revisión proporciona una base racional para toma de decisiones y desarrollo de medidas preventivas y correctivas; así como también propone los criterios mínimos de muestreo y análisis para discriminar y comparar estudios en esta problemática.
\end{abstract}

Palabras clave: Inocuidad de los alimentos; revisión sistemática; Ecuador.

\section{Systematic review of studies on food safety in Cuenca, Ecuador, period}

\section{1-2017}

Objective: To evaluate the existing evidence on food safety in the canton of Cuenca, Ecuador. Materials and methods: A systematic review of studies on food safety (microorganisms, contaminants and adulterants) was conducted during the period 1981-2017. Results: Initially, 640 studies were identified. After the analysis of the inclusion and exclusion criteria, 40 studies related to microbiological evaluations (67.5\%), pesticides, parasites and antibiotics $(7.5 \%)$, preservatives and metals $(10 \%)$ toxins $(15 \%)$ were included. Discussion: The studies emphasize the need to implement actions on hygiene and monitoring, control in handling, transport and storage, control of fresh foods whose quality is not governed by national regulations, and training of handlers and street vendors. This review provides a rational basis for decision making and development of preventive and corrective actions; as well as constituting a starting point for future research work in the region.

${ }^{1}$ PhD. Departamento de Biociencias. Grupo de Investigación Alimentación, Nutrición y Salud. Facultad de Ciencias Químicas. Universid ad de Cuenca. Cuenca, Ecuador. Av. 12 de Abril s/n Cdla. Universitaria, P.O. Box 01.01.168. Cuenca, Ecuador. Tel. +593 074051000-4124. E-mail: johana.ortiz@ucuenca.edu.ec

${ }^{2}$ MsC. Departamento de Biociencias. Grupo de Investigación Alimentación, Nutrición y Salud. Facultad de Ciencias Químicas. Universidad de Cuenca. Cuenca, Ecuador.

${ }^{3} \mathrm{PhD}$. Departamento de Biociencias. Grupo de Investigación Alimentación, Nutrición y Salud. Facultad de Ciencias Químicas. Universidad de Cuenca. Cuenca, Ecuador.

${ }^{4}$ MsC. Departamento de Biociencias. Grupo de Investigación Alimentación, Nutrición y Salud. Facultad de Ciencias Químicas. Universidad de Cuenca. Cuenca, Ecuador. 
Key words: Food safety; systematic review; Ecuador.

\section{INTRODUCCIÓN}

Los alimentos contaminados con bacterias, virus, parásitos o sustancias químicas nocivas pueden causar más de 200 tipos de enfermedades [1]. Mundialmente, se estima que alrededor de 600 millones de personas por año se enferman tras ingerir alimentos contaminados (casi 1 de cada 10 habitantes), de los cuales 420.000 mueren por la misma causa [2,3]. El problema de la falta de inocuidad de los alimentos no solo acarrea un alto índice de morbilidad y mortalidad, sino también representa un factor importante que contribuye a la reducción de la productividad económica en muchos países ${ }^{[4]}$.

Entre las principales causas de falta de inocuidad de un alimento están las prácticas agrícolas inadecuadas, la falta de higiene a lo largo de la cadena alimentaria, la ausencia de controles preventivos en las operaciones de elaboración y preparación de los alimentos, la utilización inadecuada de productos químicos, la contaminación de las materias primas y del agua, y del almacenamiento de alimentos en lugares inapropiados [5], así como también el cambio climático, los cambios en los estilos de vida de la población y su nivel socioeconómico [1,2].

Los índices de una inadecuada manipulación de alimentos en países desarrollados alcanzan un $20 \%$ [6]. El riesgo se incrementa en países en vías de desarrollo como resultado de una falta de formación continua sobre inocuidad alimentaria $[6,7]$. En particular, la venta ambulante de alimentos podría representar un riesgo potencial de intoxicación y/o infección alimentaria para el consumidor por la falta de control en el procesamiento y expendio de estos alimentos. Los medios de elaboración suelen ser poco higiénicos, con limitado acceso a agua potable y servicios sanitarios. Además, puede darse un uso incorrecto de aditivos alimentarios, así como también el incremento de la exposición de los alimentos a la contaminación ambiental [8].

Las ETA acarrean inmensas implicaciones económicas y sociales pues su costo no es fácil de visualizar o aún de estimar [9]. Sin embargo, existen algunos ejemplos de países en donde se ha logrado dicha estimación. Tal es el caso de Perú, donde la reaparición del cólera en 1991 ocasionó una pérdida de 700 millones de dólares debido a las restricciones en las exportaciones de pescado y productos pesqueros [10]. Se ha reportado que en el año 2006 se registraron 5.4 millones de episodios de ETA en Australia que costaron cerca 1.2 millones de dólares australianos; en el año 2000 se reportaron 120.000 episodios de ETA en Nueva Zelandia que generaron un costo de 88 millones de dólares americanos; y en el año 1996 se estimó que los 6.5-33 millones de episodios anuales de ETA en Estados Unidos significaron al país un gasto de 9.3-12.9 mil millones de dólares [11].

En Ecuador, así como en otros países en desarrollo, existen instituciones encargadas de la regulación y control de sistemas de gestión para asegurar la inocuidad y soberanía alimentaria del país [12]. Sin embargo, numerosas acciones a distintos niveles son necesarias para garantizar la producción inocua de los alimentos, especialmente de aquellos que son producidos artesanalmente [12, 13]. Según las estadísticas nacionales, se reportaron 34.121 casos de ETA en el

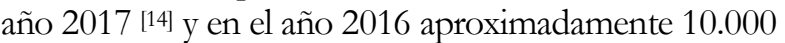
personas por año sufrieron intoxicaciones alimentarias originadas por el consumo de comida en comedores, escuelas, ventas ambulantes e inclusive el propio hogar [15]. Particularmente, en el cantón Cuenca se notificaron 650 casos de intoxicaciones alimentarias en el año 2016 [15] y se han registrado 380 casos en el año 2017 [16].

El objetivo del presente trabajo fue realizar una revisión sistemática de los estudios de diagnóstico y/o evaluación de la inocuidad alimentaria en diversos tipos de alimentos en el cantón Cuenca, Ecuador durante el período 1981 hasta 2017 con el fin de compilar información representativa, y específica de los trabajos realizados en el cantón que permitan direccionar acciones a nivel de salud pública y definir prioridades de futuros estudios de investigación y monitoreo.

\section{MATERIALES Y MÉTODOS}

Se realizó una revisión sistemática de todos los estudios primarios desarrollados en el cantón Cuenca- 
Ecuador sobre inocuidad alimentaria en áreas afines a microbiología, contaminantes y adulterantes, considerados retrospectivamente a partir de septiembre de 2017. Los objetivos y los criterios de búsqueda fueron definidos con la elaboración de un protocolo antes de iniciar con la investigación.

\section{Área de estudio}

Cuenca, ubicada al sur de la región Andina del Ecuador a 2.538 m.s.n.m., es la tercera ciudad más importante del Ecuador. Esta ciudad cuenta con una superficie de 15.730 hectáreas y una población aproximada de 580.000 habitantes [17]. La población de la región presenta un $5.2 \%$ de analfabetismo, el 18.9\% alcanza la educación superior y $44.2 \%$ forma parte de la población económicamente activa ${ }^{[18]}$.

\section{Estrategias de búsqueda}

La búsqueda de información se realizó en bases de datos digitales de PubMed y Google académico empleando los términos "inocuidad alimentaria", "microbiología de alimentos", "contaminantes de alimentos" y "adulterantes en alimentos". Además se buscaron estudios en repositorios digitales institucionales (DSpace) de las cuatro universidades del cantón Cuenca (Universidad del Azuay, Universidad Católica de Cuenca, Universidad de Cuenca y Universidad Politécnica Salesiana).

El periodo de tiempo desde el cual se recolectó la información se estableció según el primer estudio encontrado que fue enero de 1981 hasta septiembre de 2017.

\section{Criterios de elegibilidad}

Los estudios elegibles para ser incluidos en la revisión fueron aquellos que cumplían con los siguientes criterios: i) Muestreo representativo: mínimo de 15 muestras de alimentos tomadas de al menos 3 lugares distintos, y ii) Métodos y técnicas de análisis de fuentes oficiales, tales como las normas Association of Official Agricultural Chemists (AOAC), Food and Drug Administration( FDA), Instituto Ecuatoriano de Normalización (INEN) o métodos optimizados, validados y publicados en artículos científicos.

Por otro lado, los criterios de exclusión definidos fueron: i) Estudios sin la descripción sobre el cálculo del tamaño de la muestra o cuyo procedimiento de muestreo de los alimentos no esté bien establecido, ii) Estudios que sigan métodos y técnicas de análisis de laboratorio de fuentes no oficiales, iii) Estudios de la inocuidad de la materia prima y del proceso tecnológico utilizado en la elaboración del alimento o de Buenas Prácticas de Manufactura (BPM), y iv) Estudios que registren únicamente las características físico-químicas del alimento.

\section{Selección y revisión de estudios}

Inicialmente los estudios se seleccionaron en base a la revisión de títulos y resúmenes. Luego se procedió a la revisión a texto completo de los estudios seleccionados. Conforme al cumplimiento de los criterios de elegibilidad, los datos fueron extraídos y tabulados en hojas de cálculo de Microsoft Excel® 2013. Los datos registrados fueron el título del estudio, objetivos, tamaño de la muestra, métodos de análisis empleados y resultados principales de cada estudio.

\section{RESULTADOS}

Inicialmente se identificaron 640 estudios publicados desde enero de 1981 hasta septiembre de 2017 basado en las palabras claves y la localidad de los estudios (Figura 1). La mayoría fueron estudios realizados como tesis de pregrado y posgrado de la Universidad de Cuenca $(\mathrm{n}=535)$ y de la Universidad del Azuay ( $\mathrm{n}=100)$, mientras que cuatro estudios fueron realizados en la Universidad Politécnica Salesiana y un estudio correspondió a un artículo publicado en una revista indexada en SCOPUS [19]. Luego de la aplicación de los criterios de elegibilidad, de los 640 trabajos, 584 se consideraron no elegibles pues 372 correspondían a manuales de BPM y $212 \mathrm{a}$ estudios en materia prima. 
Figura 1. Diagrama de flujo del proceso de selección de estudios para la Revisión Sistemática

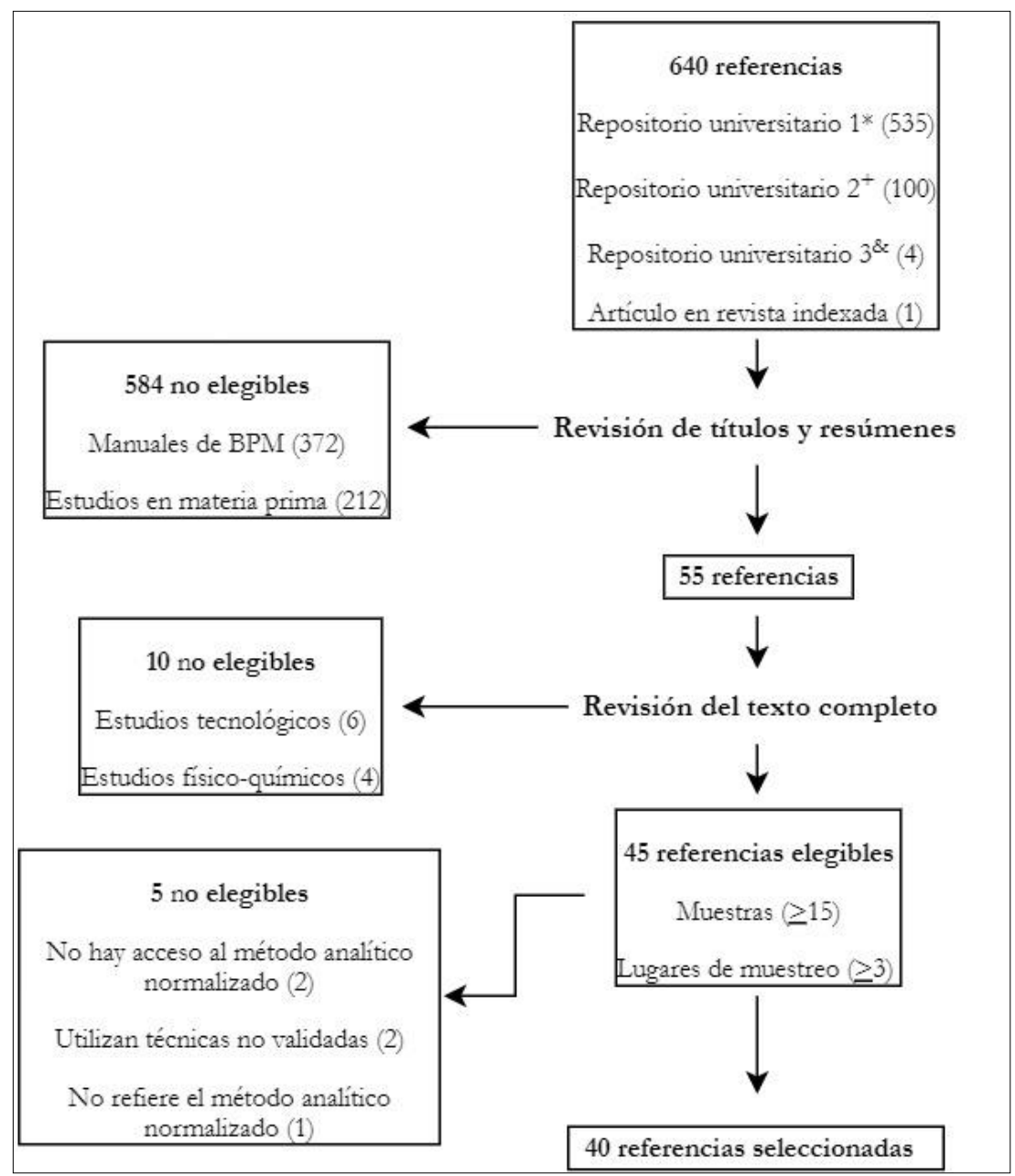

*Repositorio universitario 1 - Universidad de Cuenca

+Repositorio universitario 2 - Universidad del Azuay

\&Repositorio universitario 3 - Universidad Politécnica Salesiana

La revisión del texto completo se realizó en los 55 estudios restantes. De estos se excluyeron 10, de los cuales seis estudios se referían a la inocuidad durante el proceso de elaboración de un producto alimenticio y cuatro se basaban en características físico-químicas de los alimentos. De los 45 restantes, se descartaron cinco estudios más, ya que uno carecía del método analítico empleado, en dos estudios no fue posible constatar la veracidad de los métodos analíticos (posiblemente debido la antigüedad de estos estudios), y dos estudios en los que se emplearon técnicas analíticas no estandarizadas. Finalmente, se seleccionaron 40 estudios cuyos criterios metodológicos (muestreo y métodos analíticos) y resultados principales se presentan en orden cronológico en la Tabla 1. 
Tabla 1. Criterios metodológicos y resultados principales de los artículos analizados en la revisión sistemática en orden cronológico.

\begin{tabular}{|c|c|c|c|c|c|c|c|}
\hline Año & Objeto de análisis & $\begin{array}{c}\text { No de } \\
\text { muestras }\end{array}$ & $\begin{array}{c}\text { Alimento y } \\
\text { frecuencia de } \\
\text { muestreo }\end{array}$ & Lugares de Muestreo & Métodos de análisis & Resultados principales & Ref. \\
\hline 1986 & $\begin{array}{l}\text { Bacterias activas, } \\
\text { coliformes }\end{array}$ & 120 & $\begin{array}{c}\text { Leche pasteurizada: } \\
20 \text { de } 6 \text { marcas cada } \\
15 \text { días }\end{array}$ & $\begin{array}{c}\text { Mercados, } \\
\text { supermercados y tiendas } \\
\text { de la ciudad de Cuenca }\end{array}$ & $\begin{array}{c}\text { NTE INEN 10, 21, } \\
2337\end{array}$ & $\begin{array}{c}30 \% \text { de contaminación } \\
\text { elevada con bacterias activas }\end{array}$ & {$[20]$} \\
\hline 1991 & $\begin{array}{c}\text { Coliformes, Staphylococcus } \\
\text { spp. }\end{array}$ & 203 & $\begin{array}{c}\text { Carnes cocidas } 3 \\
\text { meses consecutivos }\end{array}$ & $\begin{array}{l}\text { Fábricas de embutidos, } \\
\text { mercados, restaurantes, } \\
\text { vendedores ambulantes } \\
\text { de la ciudad de Cuenca }\end{array}$ & $\begin{array}{c}\text { NTE INEN 765, 766, } \\
768,1338\end{array}$ & $\begin{array}{c}70 \% \text { de contaminación con } \\
\text { E. coli }\end{array}$ & {$[21]$} \\
\hline 1993 & Salmonella spp. & 260 & $\begin{array}{l}\text { Pollo crudo: } 20 \text { de } \\
\text { cada lugar por } 3 \\
\text { meses consecutivos }\end{array}$ & $\begin{array}{l}13 \text { parroquias rurales del } \\
\text { cantón Cuenca }\end{array}$ & NTE INEN 1529 & $\begin{array}{c}3.5 \% \text { de contaminación con } \\
\text { Salmonella spp. }\end{array}$ & {$[22]$} \\
\hline 1993 & $\begin{array}{c}\text { Staphylococcus, } \\
\text { Streptococcus, Pseudomona, } \\
\text { Salmonella, Shiguella, } \\
\text { Vibrio cholerae }\end{array}$ & 28 & $\begin{array}{l}\text { Bebidas: } 2 \text { meses } \\
\text { consecutivos }\end{array}$ & $\begin{array}{c}\text { Bares, restaurantes, } \\
\text { vendedores ambulantes, } \\
\text { tiendas y mercados de la } \\
\text { ciudad de Cuenca }\end{array}$ & $\begin{array}{l}\text { NTE INEN 1529, } \\
2337\end{array}$ & $\begin{array}{l}\text { 42.9\% de contaminación con } \\
\text { Staphylococcus, Streptococcus, E. } \\
\text { coli, Klebsiella y Pseudomona }\end{array}$ & [23] \\
\hline 1996 & $\begin{array}{c}\text { E. coli, S. aureus, } \\
\text { Salmonella, levaduras y } \\
\text { mohos }\end{array}$ & 15 & $\begin{array}{l}\text { Queso fresco: } 15 \\
\text { marcas en } 3 \text { meses } \\
\text { consecutivos }\end{array}$ & $\begin{array}{l}\text { Supermercados de la } \\
\text { ciudad de Cuenca }\end{array}$ & \begin{tabular}{|l|} 
NTE INEN 164, 165, \\
1529 \\
\end{tabular} & $\begin{array}{c}80 \% \text { sobrepasaron una } \\
\text { contaminación de } 100 \mathrm{UFC} / \mathrm{g} \\
\text { para S. aureus; } 44 \% \\
\text { sobrepasaron las } 50.000 \\
\text { UFC/g para mohos y } \\
\text { levaduras. } 100 \% \text { ausencia de } \\
\text { Salmonella }\end{array}$ & {$[24]$} \\
\hline 1998 & $\begin{array}{l}\text { Fosforados, } \\
\text { organoclorados, } \\
\text { nitrogenados }\end{array}$ & 105 & $\begin{array}{c}\text { Lechuga: } 3 \text { de } 5 \\
\text { unidades. }\end{array}$ & $\begin{array}{c}7 \text { mercados y } 3 \\
\text { supermercados de la } \\
\text { ciudad de Cuenca }\end{array}$ & FAO/OMS & $\begin{array}{l}88 \% \text { de contaminación con } \\
\text { residuos de pesticidas }\end{array}$ & {$[25]$} \\
\hline 2000 & $\begin{array}{l}\text { Clostridium, coliformes } \\
\text { totales y fecales, } \\
\text { Enterococcus, Pseudomona }\end{array}$ & 17 & \begin{tabular}{|c|} 
Agua embotellada: 14 \\
botellas de $500 \mathrm{ml}(4$ \\
marcas), 3 bidones de \\
$18 \mathrm{~L}, 1$ agua fresca por \\
4 meses
\end{tabular} & $\begin{array}{c}\text { Diferentes } \\
\text { supermercados de la } \\
\text { ciudad de Cuenca }\end{array}$ & $\begin{array}{c}\text { NTE INEN } \\
1334: 1986,2178: 98 \\
2337 \text { y } 2200: 98\end{array}$ & $\begin{array}{l}1 \% \text { de contaminación con } \\
\text { coliformes totales durante el } \\
\text { proceso de envasado }\end{array}$ & [26] \\
\hline 2005 & Benzoatos y nitritos & 84 & $\begin{array}{c}7 \text { de embutidos por } 3 \\
\text { marcas y por tipo, } 7 \\
\text { muestras de jugos }\end{array}$ & $\begin{array}{l}\text { Instituciones educativas } \\
\text { de la Ciudad de Cuenca }\end{array}$ & \begin{tabular}{|c|} 
AOAC 960,38. \\
Método de Grau Mirna \\
(Martínez, 1996)
\end{tabular} & $\begin{array}{c}\text { Nitritos > LMP en la norma } \\
\text { INEN en mortadelas }(5 \%) \text { y } \\
\text { vienesa ( } 57 \%) \text {, aunque dentro } \\
\text { de los LMP por la norma } \\
\text { Panamericana. } \\
\text { Benzoatos > LMP en jugos } \\
(29 \%)\end{array}$ & {$[27]$} \\
\hline 2006 & $\begin{array}{c}\text { Citrobacter, E. coli, Proteus } \\
\text { y Salmonella }\end{array}$ & 60 & 20 por tipo de huevo & $\begin{array}{c}\text { Supermercados y tiendas } \\
\text { de diferentes lugares de } \\
\text { la ciudad de Cuenca }\end{array}$ & NTE INEN 1529-15 & $\begin{array}{l}\text { Huevo al menudeo: } 11.7 \% \text { E. } \\
\text { coli, } 1.7 \% \text { Citrobacter. } \\
\text { Huevo criollo: } 11.7 \% \text { E. coli, } \\
3.3 \% \text { Proteus, } 1.7 \% \text { Citrobacter y } \\
\text { Salmonella. } \\
\text { Huevo indaves: } 10 \% \text { E. coli. }\end{array}$ & {$[28]$} \\
\hline 2006 & Aerobios mesófilos & 60 & $\begin{array}{l}\text { Leche cruda: } 10 \text { por } 6 \\
\text { semanas consecutivas }\end{array}$ & $\begin{array}{c}\text { Carros repartidores y } \\
\text { haciendas } 5 \text { parroquias } \\
\text { rurales de la ciudad de } \\
\text { Cuenca }\end{array}$ & $\begin{array}{l}\text { NTE INEN 1529-5; } \\
\text { INEN 9; } 4\end{array}$ & $\begin{array}{c}20.5 \%>\text { LMP } \\
16.8 \% \text { fuera del límite } \\
\text { especificado para la prueba de } \\
\text { TRAM }\end{array}$ & [29] \\
\hline 2008 & $\begin{array}{l}\text { Aerobios mesófilos, } \\
\text { Enterobacterias, E. coli, } \\
\text { Salmonella, S. aureus }\end{array}$ & 84 & $\begin{array}{c}\text { Salchicha escaldada: } 3 \\
\text { de } 6 \text { marcas en } 4 \\
\text { tomas. }\end{array}$ & $\begin{array}{c}3 \text { mercados y } 2 \\
\text { supermercados de la } \\
\text { ciudad de Cuenca }\end{array}$ & $\begin{array}{l}\text { NTE INEN 1338:96, } \\
\text { 1529-5:98, 1295-14:98 }\end{array}$ & $\begin{array}{l}4.1 \%>\text { LMP para aerobios } \\
\text { mesófilos. } \\
20.4 \% \text { contaminación con } \\
\text { coliformes totales. } \\
100 \% \text { ausencia de } S . \text { aureus y } \\
\text { Salmonella }\end{array}$ & {$[30]$} \\
\hline
\end{tabular}




\begin{tabular}{|c|c|c|c|c|c|c|c|}
\hline 2008 & $\begin{array}{l}\text { Coliformes totales, } \\
\text { Streptococcus termophilus, } \\
\text { Lactobacillus bulgaricus, } \\
\text { levaduras y mohos }\end{array}$ & 6 & $\begin{array}{c}1 \text { de yogur natural y } 1 \\
\text { de yogur de mora por } \\
\text { tres meses } \\
\text { consecutivos }\end{array}$ & $\begin{array}{c}\text { No menciona los lugares } \\
\text { de procedencia de las } \\
\text { muestras }\end{array}$ & \begin{tabular}{|c|} 
NTE INEN 14, 170, \\
171,172
\end{tabular} & $\begin{array}{c}72 \% \text { yogur natural y } 83 \% \text { yogur } \\
\text { de mora no cumplieron con el } \\
\text { LMP de acidez. } \\
100 \% \text { ausencia de coliformes. } \\
94 \% \text { > LMP para mohos y } \\
\text { levaduras }\end{array}$ & [31] \\
\hline 2012 & $\begin{array}{l}\text { Aerobios mesófilos, } \\
\text { coliformes totales y } \\
\text { fecales, levaduras y } \\
\text { mohos }\end{array}$ & 34 & $\begin{array}{l}\text { Bebidas frías de } \\
\text { frutas: } 3 \text { muestreos } \\
\text { en marzo, abril y } \\
\text { mayo del } 2012\end{array}$ & $\begin{array}{c}3 \text { campus de la } \\
\text { Universidad de Cuenca. }\end{array}$ & NTE INEN 2337:08 & $\begin{array}{c}100 \%>\text { LMP de la norma } \\
\text { INEN } 2337\end{array}$ & [32] \\
\hline 2013 & E. coli, Salmonella spp. & 44 & $\begin{array}{c}\text { Alimentos en } \\
\text { guarderías: } 1 \text { vez por } \\
\text { semana cada } \\
\text { guardería, de lunes a } \\
\text { miércoles desde el } 8 \\
\text { al } 24 \text { de octubre }\end{array}$ & $\begin{array}{l}9 \text { centros de desarrollo } \\
\text { infantil }\end{array}$ & $\begin{array}{c}\text { Norma Peruana de } \\
\text { calidad sanitaria e } \\
\text { inocuidad para los } \\
\text { alimentos y bebidas de } \\
\text { consumo humano Art } \\
\text { 15.1 y } 15.2 \\
\text { NTE INEN 1529- } \\
\text { 15:2009 }\end{array}$ & $\begin{array}{l}59.1 \% \text { contaminación con } \\
\text { coliformes } \\
18.2 \% \text { con E. coli y } 100 \% \text { de } \\
\text { ausencia de Salmonella. }\end{array}$ & [33] \\
\hline 2013 & $\begin{array}{l}\text { Coliformes totales, } E \text {. } \\
\text { coli, mesófilos totales }\end{array}$ & 139 & $\begin{array}{l}68 \text { de carne molida } \\
\text { de cerdo y } 71 \text { de } \\
\text { carne molida de } \\
\text { pollo }\end{array}$ & $\begin{array}{l}\text { Mercados principales de } \\
\text { la ciudad de Cuenca }\end{array}$ & NTE INEN 1338:12 & $\begin{array}{l}\text { Identificación de E. coli en } \\
\text { carnes crudas por } \\
\text { espectroscopia infrarroja, } \\
\text { clasificación KNN y } \\
\text { algoritmo genético. }\end{array}$ & [34] \\
\hline 2013 & $\begin{array}{l}\text { Enterobacterias, } \\
\text { Salmonella spp. }\end{array}$ & 48 & $\begin{array}{c}\text { Chuzos y aderezos: } 4 \\
\text { semanas de } \\
\text { septiembre, de } \\
\text { domingo a martes }\end{array}$ & $\begin{array}{c}2 \text { parroquias urbanas del } \\
\text { cantón Cuenca. }\end{array}$ & NTE 1529-15-96 & $\begin{array}{l}42 \% \text { de contaminación con } \\
\text { E. coli, } 17 \% \text { con Proteus } \\
\text { vulgaris, } 13 \% \text { con Enterobacter } \\
\text { aerogenes y } 8 \% \text { con Enterobacter } \\
\text { cloacae. } \\
100 \% \text { ausencia de Salmonella. }\end{array}$ & [35] \\
\hline 2013 & Aflatoxinas & 30 & $\begin{array}{c}\text { Cereales al granel: } 5 \\
\text { meses }\end{array}$ & $\begin{array}{l}\text { Mercado principal de la } \\
\text { ciudad de Cuenca. }\end{array}$ & $\begin{array}{l}\text { AOAC USDA- } \\
\text { GIPSA 2008-011 }\end{array}$ & $\begin{array}{c}100 \% \text { dentro del límite de la } \\
\text { norma AOAC USDA- } \\
\text { GIPSA 2008-011 }\end{array}$ & [36] \\
\hline 2013 & Ocratoxina A & 87 & $\begin{array}{c}\text { Chocolate de hoja: } 15 \\
\text { semanas }\end{array}$ & $\begin{array}{l}2 \text { mercados principales } \\
\text { de la ciudad de Cuenca. }\end{array}$ & $\begin{array}{l}\text { LMP Normativa } \\
\text { Brasilera }\end{array}$ & $96.6 \%>$ LMP (5ppb) & [37] \\
\hline 2013 & Aerobios mesófilos & 82 & $\begin{array}{c}\text { Leche cruda: distintas } \\
\text { fechas (no } \\
\text { especificadas) }\end{array}$ & $\begin{array}{c}\text { Carros repartidores de } 5 \\
\text { zonas rurales aledañas al } \\
\text { cantón Cuenca. }\end{array}$ & INEN 9:2012 & $43.9 \%>\mathrm{LMP}$ & [38] \\
\hline 2013 & $\begin{array}{l}\text { Staphylococcus aureus, } \\
\text { enterobacterias, } \\
\text { levaduras y mohos }\end{array}$ & 25 & $\begin{array}{c}\text { Dulce de leche: } 5 \\
\text { puntos de expendio, } \\
\text { por cinco semanas } \\
\text { consecutivas }\end{array}$ & $\begin{array}{l}\text { Mercado principal de la } \\
\text { ciudad de Cuenca. }\end{array}$ & $\begin{array}{c}\text { NTE INEN 4, 14, 700, } \\
164,398,1529\end{array}$ & $\begin{array}{c}100 \% \text { ausencia de } \\
\text { enterobacterias y } \\
\text { Staphylococcus. } \\
100 \% \text { de contaminación con } \\
\text { mohos y levaduras. }\end{array}$ & [39] \\
\hline 2013 & $\begin{array}{l}\text { Coliformes totales, } E \text {. } \\
\text { coli. }\end{array}$ & 96 & $\begin{array}{l}\text { Lechuga: } 32 \text { en } 3 \\
\text { periodos }\end{array}$ & $\begin{array}{l}4 \text { mercados principales } \\
\text { de la ciudad de Cuenca. }\end{array}$ & \begin{tabular}{|c|} 
Recopilación \\
Internacional de \\
Normas \\
Microbiológicas de los \\
Alimentos y \\
Asimilados de Moragas \\
y col. \\
\end{tabular} & $\begin{array}{l}100 \% \text { de contaminación con } \\
\text { coliformes totales. } \\
6.3 \% \text { con de } E \text {. coli }>\text { LMP }\end{array}$ & [40] \\
\hline 2013 & Nitritos & 259 & $\begin{array}{c}\text { Salchicha tipo } \\
\text { Frankfurt: } 92 \text { lugares } \\
\text { de muestreo }\end{array}$ & $\begin{array}{l}6 \text { mercados principales } \\
\text { de la ciudad de Cuenca. }\end{array}$ & $\begin{array}{c}\text { NTE INEN 0784: 85, } \\
\text { 1985, 1996, 2012, } \\
1338: 96\end{array}$ & $10 \%>\mathrm{LMP}$ & [41] \\
\hline 2013 & $\begin{array}{c}\text { Aflatoxina } \mathrm{B}_{1}\left(\mathrm{AFB}_{1}\right) \\
\mathrm{B}_{2}, \mathrm{G}_{1}, \mathrm{G} 2 \text {, ocratoxina } \\
\text { A (OTA), } \\
\text { deoxinivalenol }(\mathrm{DON}) \\
\text { fumonisina } \mathrm{B}_{1}, \\
\text { zearalenona, HT2, T2 }\end{array}$ & 198 & $\begin{array}{c}70 \text { de hojuelas de } \\
\text { avena, } 63 \text { de fideos } \\
\text { de trigo blanco y } 65 \\
\text { de fideos de trigo } \\
\text { amarillo }\end{array}$ & $\begin{array}{c}\text { Mercados y } \\
\text { supermercados en } \\
\text { Cuenca (muestreo } \\
\text { también realizado en el } \\
\text { cantón Nabón y las } \\
\text { provincias arroceras del } \\
\text { país). }\end{array}$ & $\begin{array}{c}\text { Métodos validados por } \\
\text { Ortiz et al, } 2013\end{array}$ & $\begin{array}{c}\text { En fideos de trigo blanco: } \\
33 \% \text { DON y } 5 \% \text { de OTA. } \\
\text { En fideos de trigo amarillo: } \\
5 \% \text { DON } \\
\text { En hojuelas de avena: } 17 \% \\
\text { DON, } 2 \% \text { OTA y } 2 \% \mathrm{AFB}_{1} .\end{array}$ & [19] \\
\hline
\end{tabular}




\begin{tabular}{|c|c|c|c|c|c|c|c|}
\hline 2014 & $\begin{array}{l}\text { Cadmio, cobre, plomo, } \\
\text { zinc. }\end{array}$ & 25 & $\begin{array}{l}\text { Cerveza: Noviembre- } \\
\text { diciembre } 2013 \text { y } \\
\text { Enero-Febrero } 2014 .\end{array}$ & $\begin{array}{c}6 \text { puntos de expendio en } \\
\text { la ciudad de Cuenca }\end{array}$ & $\begin{array}{c}\text { AOAC 920.49; AOAC } \\
\text { 900.02; INEN } \\
2262: 2003 \\
\end{array}$ & $\begin{array}{l}\text { Análisis clúster para cerveza. } \\
\text { Clúster } 1,2,4(73 \%) \\
\text { cumplen con la normativa } \\
\text { para } \mathrm{Zn}, \mathrm{Cu} \text { y } \mathrm{Pb} \text {. Clúster } 3 \text { y } \\
6(5 \%) \text { cumplen la norma } \\
\text { para } \mathrm{Zn} \text {, y } \mathrm{Cu} \text {, pero } \\
\text { sobrepasa el límite para } \mathrm{Pb} \text {. } \\
\text { Clúster } 5 \text { y } 8(20 \%) \text { cumplen } \\
\text { para } \mathrm{Zn} \text { y Pb, pero sobrepasa } \\
\text { el límite para Cu. Clúster } 7 \\
(2 \%) \text { normal para Cu y } \mathrm{Pb}, \\
\text { pero supera límites para } \mathrm{Zn} \text {. } \\
100 \% \text { cumplen con la norma } \\
\text { vigente brasileña para } \mathrm{Cd} \text {. }\end{array}$ & [42] \\
\hline 2014 & $\begin{array}{l}\text { Aerobios mesófilos, } \\
\text { coliformes totales, } E \text {. } \\
\text { coli, levaduras y mohos. }\end{array}$ & 55 & $\begin{array}{c}\text { Chocho } \\
\text { desamargado: } \\
\text { muestreo aleatorio }\end{array}$ & $\begin{array}{c}\text { Establecimientos } \\
\text { educativos de } 15 \\
\text { parroquias urbanas de la } \\
\text { ciudad de Cuenca }\end{array}$ & NTE INEN 2390:2004 & $\begin{array}{c}83.6 \% \text { con coliformes totales } \\
25.5 \% \text { con } E \text {. coli, } \\
56.4 \% \text { con mesófilos } \\
\text { aerobios, } \\
94.5 \% \text { con mohos y } \\
\text { levaduras. } \\
\end{array}$ & [43] \\
\hline 2014 & Salmonella spp. & 75 & \begin{tabular}{|c|} 
Mayonesa en \\
pollerías: 3 muestras \\
de 25 locales: 15 en el \\
primer periodo y 60 \\
en el segundo.
\end{tabular} & $\begin{array}{c}25 \text { locales del centro } \\
\text { histórico de la ciudad de } \\
\text { Cuenca. }\end{array}$ & NTE INEN 2295 & $\begin{array}{c}100 \% \text { ausencia de Salmonella } \\
\text { spp. }\end{array}$ & [44] \\
\hline 2014 & Listeria monocytogenes & 60 & $\begin{array}{c}\text { Queso fresco: } 2 \\
\text { muestras de } 15 \\
\text { locales: } 2 \text { entre } \\
\text { semana y } 3 \text { en fin de } \\
\text { semana. }\end{array}$ & $\begin{array}{l}4 \text { mercados principales } \\
\text { de la ciudad de Cuenca. }\end{array}$ & $\begin{array}{l}\text { AOAC 2004: 06; } \\
\text { INEN 1528-2012 }\end{array}$ & $\begin{array}{c}100 \% \text { ausencia de Listeria } \\
\text { monocytogenes. }\end{array}$ & [45] \\
\hline 2015 & $\begin{array}{c}\text { E. coli, Listeria spp. } \\
\text { Salmonella spp., S. aureus }\end{array}$ & 72 & $\begin{array}{c}\text { Salchicha tipo } \\
\text { Frankfurt: } 3 \text { marcas } \\
\text { de } 12 \text { puestos, de } \\
\text { octubre a diciembre } \\
\text { de } 2013 .\end{array}$ & $\begin{array}{l}\text { Mercado principal de la } \\
\text { ciudad de Cuenca. }\end{array}$ & $\begin{array}{l}\text { INEN NTE } 1338 . \\
\text { validado por AOAC }\end{array}$ & $\begin{array}{l}\text { 8.3\% con Providencia } \\
\text { rustigianii, } 2.7 \% \text { con } \\
\text { Acinetobacter iwoffi y } 5.5 \% \text { con } \\
\text { Shigella serogrupo A, B y C. }\end{array}$ & [46] \\
\hline 2015 & E. coli, S. aureus. & 45 & $\begin{array}{c}\text { Comida rápida: } 5 \\
\text { muestras en } \\
\text { diferentes días de } 9 \\
\text { locales de octubre a } \\
\text { diciembre de } 2012 .\end{array}$ & $\begin{array}{l}\text { Avenida principal de la } \\
\text { ciudad de Cuenca. }\end{array}$ & $\begin{array}{l}\text { Norma peruana 615- } \\
2003 \text { SA/DM de } \\
\text { DIGESA }\end{array}$ & $\begin{array}{l}66.7 \% \text { no cumple la norma } \\
\text { referida para E coli. } \\
100 \% \text { cumple con la } \\
\text { normativa para } S . \text { aureus. }\end{array}$ & [47] \\
\hline 2015 & Campylobacter spp. & 75 & $\begin{array}{c}\text { Carcasa de pollo } \\
\text { fresco: } 7 \text { a } 14 \text { de } \\
\text { septiembre de } 2015 .\end{array}$ & $\begin{array}{l}2 \text { mercados principales } \\
\text { de la ciudad de Cuenca. }\end{array}$ & ISO 10 272-1995 & $44 \%$ de contaminación & [48] \\
\hline 2016 & Aflatoxina $\mathrm{M}_{1}$ & 84 & $\begin{array}{c}2 \text { de leche cruda, } 4 \text { de } \\
\text { pasteurizada y } 36 \text { de } \\
\text { ultra pasteurizada. }\end{array}$ & $\begin{array}{l}3 \text { supermercados de la } \\
\text { ciudad de Cuenca. }\end{array}$ & $\begin{array}{l}\text { INEN NTE 9-10: } \\
2012\end{array}$ & $19 \%$ positivas para $\mathrm{AF} \mathrm{M}_{1}$. & [49] \\
\hline 2016 & $\begin{array}{l}\text { Aerobios mesófilos, } \\
\text { Salmonella. }\end{array}$ & 70 & $\begin{array}{c}\text { Cuyes: } 14 \text { de Cuenca, } \\
25 \text { de Nabón y } 31 \text { de } \\
\text { Ibarra. }\end{array}$ & $\begin{array}{l}\text { Criaderos de cuyes en } \\
\text { Cuenca (muestreo } \\
\text { también realizado en el } \\
\text { cantón Nabón y en el } \\
\text { cantón de Ibarra). }\end{array}$ & $\begin{array}{l}\text { AOAC 960801; } \\
\text { Norma peruana } \\
201.0582006\end{array}$ & $\begin{array}{c}64.3 \%>\text { LMP para aerobios } \\
\text { mesófilos del criadero de } \\
\text { Cuenca. } \\
57.1 \% \text { positivas para } \\
\text { Salmonella }\end{array}$ & [50] \\
\hline 2016 & $\begin{array}{l}\text { Helmintos (Taenia y } \\
\text { Trichuris) y Protozoos } \\
\text { (Entamoeba histolytica y } \\
\text { Giardia lambia). }\end{array}$ & 70 & $\begin{array}{l}\text { Frutilla: Febrero - } \\
\text { Marzo, } 2016\end{array}$ & $\begin{array}{l}2 \text { zonas de cultivo en } \\
\text { una parroquia rural del } \\
\text { cantón Cuenca. }\end{array}$ & $\begin{array}{l}\text { Método modificado } \\
\text { Traviezo L., } 2004\end{array}$ & $\begin{array}{l}91.4 \% \text { contaminadas, en su } \\
\text { mayoría Entamoeba bistolytica. }\end{array}$ & [51] \\
\hline 2016 & $\begin{array}{l}\text { Coliformes, E. coli y } \\
\text { E. coli O157:H7. }\end{array}$ & 60 & $\begin{array}{c}\text { Ensaladas frescas: } \mathrm{No} \\
\text { especificado }\end{array}$ & \begin{tabular}{|c|}
16 puestos de 2 \\
mercados principales de \\
la ciudad de Cuenca.
\end{tabular} & $\begin{array}{l}\text { AOAC 2000.13; } \\
\text { AOAC 2000.14 }\end{array}$ & $\begin{array}{l}15 \% \text { positivas para E. coli } \\
\text { O157:H7 } \\
100 \% \text { > LMP para E. coli y } \\
\text { coliformes. }\end{array}$ & [52] \\
\hline 2016 & Aflatoxina $\mathrm{M}_{1}$ & 33 & $\begin{array}{c}\text { Quesillo artesanal: } 21 \\
\text { muestras } \\
\text { estratificadas }\end{array}$ & $\begin{array}{l}4 \text { mercados principales } \\
\text { de la ciudad de Cuenca. }\end{array}$ & $\begin{array}{l}\text { Normativa brasilera: } \\
\text { Ministerio de Salud, } \\
2011\end{array}$ & $\begin{array}{c}21 \% \text { positivas con máxima } \\
\text { concentración de } 0.83 \mu \mathrm{g} / \mathrm{kg} \text {. } \\
100 \%<\mathrm{LMP}\end{array}$ & [53] \\
\hline
\end{tabular}




\begin{tabular}{|c|c|c|c|c|c|c|c|}
\hline 2016 & Histamina & 210 & $\begin{array}{c}\text { Pescado fresco: } 10 \mathrm{de} \\
25 \text { locales existentes, } \\
\text { cada } 15 \text { días. }\end{array}$ & $\begin{array}{l}\text { Mercado principal de la } \\
\text { ciudad de Cuenca. }\end{array}$ & FDA & $\begin{array}{c}50 \%>\text { LMP por la FDA } \\
\quad(\leq 17 \mathrm{ppm})\end{array}$ & [54] \\
\hline 2017 & Clostridium perfringens & 62 & \begin{tabular}{|c|}
$\begin{array}{c}\text { Cerdo horneado: } 12 \\
\text { muestras de } 6 \\
\text { puestos por } 3 \\
\text { semanas }\end{array}$ \\
\end{tabular} & $\begin{array}{c}\text { Segundo mercado } \\
\text { principal de la ciudad de } \\
\text { Cuenca }\end{array}$ & $\begin{array}{l}\text { NTE 1529-2:2013. } \\
\text { Norma peruana № } \\
\text { 615-2003 SA/DM }\end{array}$ & $24 \%$ de contaminación & [55] \\
\hline 2017 & \begin{tabular}{|c|} 
Betalactámicos, \\
tetraciclinas, sulfamidas, \\
peróxido de hidrógeno y \\
neutralizantes.
\end{tabular} & 90 & \begin{tabular}{|c|} 
Leche cruda: 3 de \\
centros de acopio, en \\
tres visitas, cada 15 \\
días.
\end{tabular} & $\begin{array}{l}\text { Cuenca, Girón, Paute, } \\
\text { Sevilla de Oro, Nabón, } \\
\text { Sigsig, Pucará. }\end{array}$ & $\begin{array}{c}\text { NTE INEN } \\
\text { 1500:2011, 9:2012y } \\
\text { Codex Alimentarius }\end{array}$ & $\begin{array}{l}13.3 \% \text { de contaminación con } \\
\text { antibióticos betalactámicos. } \\
100 \% \text { ausencia de sulfonamidas } \\
\text { y tetraciclinas. } 16.4 \% \text { con } \\
\text { peróxido de hidrógeno y } 60 \% \\
\text { con neutralizantes. }\end{array}$ & [56] \\
\hline 2017 & S. aureus & 26 & $\begin{array}{l}\text { Mayonesa: Julio- } \\
\text { septiembre del 2016, } \\
\text { los días lunes, } \\
\text { miércoles y viernes. }\end{array}$ & $\begin{array}{c}\text { Locales de expendio de } \\
\text { alimentos del Terminal } \\
\text { Terrestre. }\end{array}$ & $\begin{array}{l}\text { NTE INEN } 152 \text { 9- } \\
\text { 14:98 }\end{array}$ & $19.2 \%$ de contaminación & [57] \\
\hline 2017 & Plomo, arsénico & 32 & $\begin{array}{c}\text { Cangrejo (tejido } \\
\text { blando): sábados de } \\
\text { la tercera semana de } \\
\text { junio, julio y } \\
\text { septiembre de 2016. }\end{array}$ & El Arenal & $\begin{array}{l}\text { UE Reglamento } \\
\text { (CE)№ } 1881 \text { 12-06 }\end{array}$ & $\begin{array}{c}6.3 \% \text { sobrepasó el límite } \\
\text { semanal permisible propuesto } \\
\text { por la FAO- OMS para Pb } \\
(25 \mu \mathrm{g} / \mathrm{kg}) \mathrm{Pb} \text { y As }(15 \mu \mathrm{g} / \mathrm{kg})\end{array}$ & [58] \\
\hline
\end{tabular}

Los estudios evaluados fueron muy heterogéneos en cuanto a procedimientos analíticos y objetivo de análisis. De estos, 11 correspondieron a estudios en carnes y derivados, 10 en leche y derivados, 4 en bebidas alcohólicas y analcohólicas, 4 en frutas y hortalizas, 2 en cereales y derivados, 3 en huevos y derivados, 1 en leguminosas, 1 en productos de origen marino y 4 en productos misceláneos como ensaladas frescas, chocolate y alimentos preparados en establecimientos fijos y ambulantes.

La mayoría de los estudios $(\mathrm{n}=27)$ correspondieron a evaluaciones microbiológicas principalmente de coliformes, Escherichia coli, Salmonella spp. y aerobios mesófilos en diferentes grupos de alimentos. En particular, se reportó una alta prevalencia de contaminación por coliformes y Escherichia coli $(n=14)$ en hortalizas, bebidas, leguminosas y misceláneos (ensaladas frescas y alimentos preparados); mientras que un elevado porcentaje de aerobios mesófilos ( $\mathrm{n}=6)$ se reportó en leguminosas y en bebidas. En cuanto a estudios sobre la contaminación con Salmonella $(\mathrm{n}=10)$ en distintos alimentos, en 3 se reportó la presencia de esta bacteria. Por otro lado, la leche fue el alimento más evaluado en estos estudios, mostrando un incremento en la prevalencia de contaminación microbiológica a lo largo de los años. Además, se han evaluado otros agentes en la leche, tales como aflatoxina $\mathrm{M}_{1} \mathrm{y}$ antibióticos.
En menor medida, la revisión incluye estudios sobre la contaminación con pesticidas $(\mathrm{n}=1)$, uso incorrecto de conservantes $(n=2)$, toxinas $(n=6)$, metales $(n=2)$, parásitos $(n=1)$ y antibióticos $(n=1)$.

Con respecto a los métodos analíticos, el $52,5 \%$ de los estudios ( $\mathrm{n}=21$ ) estuvieron basados en los métodos descritos en la normativa del Instituto Ecuatoriano de Normalización (INEN). En otras investigaciones los métodos de análisis estuvieron basados en lo descrito por la AOAC $(n=3)$, ISO $(n=1)$, FAO/OMS ( $n=1)$, FDA ( $n=1)$, Unión Europea $(n=1)$, Normativa Peruana $(n=1)$, Normativa Brasileña $(n=2)$, métodos modificados y validados $(n=2)$ y en otros se utilizan paralelamente métodos basados en normas nacionales e internacionales $(\mathrm{n}=7)$.

En cuanto al alcance de los estudios, en general se concluye sobre la necesidad de implementar medidas de higiene y acciones de monitoreo, control de la calidad microbiológica y control en la manipulación, transporte y almacenamiento. En algunos se enfatiza la necesidad de realizar otra metodología que incluya un mayor número de muestras y la periodicidad de los controles, considerando incluso la variación del clima. Además, algunas investigaciones resaltan la necesidad de control de los alimentos frescos cuya calidad no está regida por normativas nacionales, así como también evaluar la presencia de otros agentes nocivos, químicos o microbiológicos, diferentes al objeto de estudio. Finalmente, se destaca la necesidad de capacitar a los 
manipuladores y vendedores ambulantes como una medida de prevención de la contaminación.

\section{DISCUSIÓN}

El presente trabajo es la primera revisión sistemática de estudios sobre inocuidad alimentaria realizada en la región. Esta revisión incluyó trabajos de investigación sobre la evaluación química y microbiológica de diversos alimentos desde enero de 1981 hasta septiembre de 2017, principalmente provenientes de repositorios digitales universitarios. Aunque la mayoría de los estudios realizaron evaluaciones microbiológicas, se debe considerar que existiría un riesgo potencial de que algunos alimentos estén contaminados con otros patógenos que eventualmente no fueron objeto de su análisis. Por lo que el control periódico de la inocuidad de alimentos susceptibles a contaminarse y que son de alto consumo, tales como lácteos y carnes, debería considerarse prioritario. Además, se recomienda realizar evaluaciones de alimentos emergentes de producción artesanal y de venta ambulante que no requieren de registros sanitarios ni filtros de control para su expendio. Más aún, esta medida debería ir acompañada de actividades de capacitación sobre inocuidad alimentaria y buenas prácticas de higiene a los manipuladores de alimentos.

Los estudios encontrados en esta revisión sistemática reportan niveles de contaminación considerables en los alimentos analizados, lo que denota la manipulación inadecuada y la escasa vigilancia sanitaria y podría estar estrechamente relacionado con el incremento de 25.000 casos de ETA en los últimos 20 años en la ciudad de Cuenca ${ }^{[14] .}$

La falta de inocuidad de los alimentos constituye un progresivo problema de salud pública agudizado por la globalización de los mercados y la complejidad del control a lo largo de la cadena alimentaria industrial y artesanal. Por lo tanto, definir vías efectivas para el diagnóstico y evaluación de la inocuidad alimentaria resulta primordial para atacar esta problemática.

La revisión de investigaciones ya realizados a nivel regional podría constituir una de estas vías. Existen escasas revisiones sistemáticas sobre inocuidad alimentaria en Latinoamérica, caracterizadas especialmente por su enfoque en brotes de microorganismos específicos. Por ejemplo, en un estudio sobre vigilancia de brotes de EPA en Chile se atribuyó el 34.1\% de los casos a la mala manipulación del alimento y el $11.3 \%$ a deficiencias en el proceso de producción [59]. En otra revisión realizada en Colombia, se evaluaron los brotes de ETA por Salmonella spp., Staphylococcus aureus y Listeria monocytogenes asociados al consumo de pollo, observándose una fuerte asociación entre el consumo de pollo de asadero en restaurantes y los brotes de enfermedad por salmonelosis [00]. Otra revisión del mismo país se enfocó en los brotes de ETA por Listeria monocytogenes en brócoli y coliflor, evidenciándose la falta de información y lo complicado que resulta dimensionar esta problemática a nivel nacional [61]. Este tipo de revisiones contribuyen como punto de partida para el desarrollo de propuestas de políticas públicas. En este contexto, cabe destacar una investigación realizado en México en el que se resalta la necesidad de contar con una línea base e indicadores claros para evaluar eficazmente los problemas relacionados a la seguridad alimentaria ${ }^{[62]}$.

La principal limitación de esta revisión fue llevar a cabo el primer filtro de selección de estudios pues se evidenciaron problemas de redacción y ambigüedad en la presentación de resultados, lo que dificultó la sistematización en la recolección de datos y deja de manifiesto la necesidad de unificar criterios metodológicos para estos trabajos.

\section{CONCLUSIÓN}

La presente revisión sistemática demuestra que la inocuidad alimentaria ha sido un tema de preocupación en la academia a nivel regional desde hace más de tres décadas. Sin embargo, la mayoría de estos trabajos de investigación han pasado desapercibidos por las agentes de control por desconocimiento, falta de difusión de resultados de investigación y deficiente comunicación de riesgos. Por lo tanto, se espera que el presente estudio sirva como una base racional para la toma de decisiones y desarrollo de medidas preventivas y correctivas en cuanto a inocuidad de alimentos en la región. Por otro lado, en esta revisión se propone los criterios mínimos de métodos y técnicas de muestreo y de análisis que permitir discriminar y comparar los resultados de las diferentes investigaciones realizadas. 


\section{AGRADECIMIENTOS}

Al Grupo de Investigación "Alimentación, Nutrición y Salud" del Departamento de Biociencias de la Universidad de Cuenca. De manera especial, se agradece a las estudiantes Diana Cárdenas y Diana Contreras por el trabajo de recolección y tabulación de datos.

\section{REFERENCIAS}

[1] Bravo F. El manejo higiénico de los alimentos: Guía para la obtención del distintivo H. México: Limusa; 2004.

[2] Bari L, Ukuku D. Foodborne Pathogens and Food Safety. Food Biology Series. Estados Unidos: CRC Press; 2016.

[3] FAO/OMS. Foro Mundial FAO/OMS de autoridades de reglamentación sobre inocuidad de los alimentos. Bangkok: FAO; 2004.

[4] Caswell J. Economics of food safety. Massachusetts: Springer Science \& Business Media; 2012.

[5] Heymann D. El control de las enfermedades transmisibles. Vol. 613. Washington DC: Pan American Health Org; 2005.

[6] FAO/SAGARPA. Panorama de la seguridad alimentaria y nutricional en México. México: FAO; 2012.

[7] Briz J. Seguridad alimentaria y trazabilidad, in ETSI Agrónomos. Madrid: Universidad Politécnica de Madrid; 2004

[8] Cardoso R, Companion M, Marras S. Street food: Culture, economy, health and governance. New York: Earthscan from Routledge; 2014.

[9] Kopper G. Enfermedades Transmitidas por Alimentos y su impacto socioeconómico: Estudios de caso en Costa Rica, El Salvador, Guatemala, Honduras y Nicaragua. Vol. 6. Roma: FAO; 2009.

[10] Maguiña C. et al. Historia del cólera en el Perú en 1991. Acta Médica Peruana. 2010; 27:212-217.

[11] Molins R. El costo invisible de las enfermedades transmitidas. San José: Instituto Interamericano de Cooperación para la Agricultura; 2007.

[12] Agrocalidad, Programa de certificación, seguimiento y recertificación de unidades de producción en Buenas
Prácticas Agropecuarias a nivel nacional. Quito: Ministerio de Agricultura y Ganadería; 2017.

[13] ARCSA - Agencia de Regulación, Control y Vigilancia Sanitaria. Reglamento para el control sanitario de alimentos que se expenden en la vía pública. Ecuador: Ministerio de Salud; 2017.

[14] MSP. Anuario de Vigilancia Epidemiológica 1994-2017. Pichincha: Dirección Nacional de Vigilancia Epidemiológica; 2017.

[15] MSP. Gaceta epidemiológica semanal. Subsecretaria de Vigilancia de la Salud Pública. Pichincha: Dirección Nacional de Vigilancia Epidemiológica; 2016.

[16] MSP. Gaceta epidemiológica semanal. Subsecretaría de Vigilancia de la Salud Pública. Pichincha: Dirección Nacional de Vigilancia Epidemiológica; 2017.

[17] Municipalidad-de-Cuenca. Información territorial del Cantón Cuenca. Cuenca: GAD Municipal; 2017.

[18] INEC. Estadística del nivel de instrucción y socioeconómico. Ecuador: Instituto Nacional de Estadística y Censos - INEC; 2016.

[19] Ortiz J. et al. Mycotoxin co-occurrence in rice, oat flakes and wheat noodles used as staple foods in Ecuador. Food Addit Contam A. 2013; 30(12):2165-2176.

[20] Goyo V, Astudillo E, Salinas H. Análisis físico químico y bacteriológico de leches pasteurizadas expendidas en la ciudad de Cuenca. Ecuador: Universidad de Cuenca; 1986.

[21] Abril J, Andino G. Determinación de estafilococos y grupo coliforme en carnes cocidas que se expenden en la Ciudad de Cuenca. Ecuador: Universidad de Cuenca; 1991.

[22] Pesántez M, Suconota D, Torres L. Determinación del índice de salmonella en carne cruda de pollo. Cuenca: Universidad de Cuenca; 1993.

[23] Andrade E, Macancela R. Análisis bacteriológico de las bebidas de consumo humano en la ciudad de Cuenca. Cuenca: Universidad de Cuenca; 1993.

[24] Cárdenas F, Pesántez I, Torres D. Control de calidad analítico de quesos frescos que se expenden en los supermercados de la ciudad de Cuenca. Cuenca: Universidad de Cuenca; 1996. 
[25] Pineda-González S. Niveles residuales de pesticidas en la lechuga lactuca sativa variedad capitana que se consume en Cuenca. Cuenca: Universidad de Cuenca; 1998.

[26] Moscoso-Orellana P, Morocho-Yaguana L. Estudio microbiológico de cinco marcas de agua de mesa sin gas que se expenden en la ciudad de Cuenca. Cuenca: Universidad de Cuenca; 2000.

[27] Coronel-Campoverde A, Salamea-Cordero M. Determinación de conservantes en bebidas y embutidos consumidos en la ciudad de Cuenca. Cuenca: Universidad de Cuenca; 2005.

[28] Egüez J, Escobar H. Investigación de salmonella en huevos de gallina (h. al menudeo, h. criollos, h. indaves) que se expenden en la ciudad de Cuenca. Cuenca: Universidad de Cuenca; 2006.

[29] Pacheco-García T, Tello-Nieto T. Control microbiológico de la leche cruda producida en el sector de Sayausí. Cuenca: Universidad de Cuenca; 2006.

[30] Feicán-Espinoza F, Tamayo-Ramos A. Monitoreo de la calidad microbiológica de la salchicha escaldada que se expande en la Ciudad de Cuenca. Cuenca: Universidad de Cuenca; 2008.

[31] Paucar-Sánchez L. Evaluación de la calidad de seis yogures sin marca comercial que se expenden en la ciudad de Cuenca. Cuenca: Universidad de Cuenca; 2008.

[32] Cacay-Torres B, Torres-Luzuriaga A. Calidad microbiológica de bebidas frías de frutas consumidas en los bares y/o comedores de la Universidad de Cuenca. Cuenca: Universidad de Cuenca; 2012.

[33] León-Vizñay J. Determinación de Salmonella y Escherichia coli en alimentos preparados en guarderías municipales de Cuenca. Cuenca: Universidad del Azuay; 2013.

[34] Rosales-Medina M. Determinación del deterioro microbiano de la carne molida de cerdo y pollo aplicando espectroscopia infrarroja. Cuenca: Universidad del Azuay, 2013.

[35] Cobeña N. Salmonella en comidas rápidas (Chuzos y aderezos) de venta en la vía pública de la Ciudad de Cuenca. Cuenca: Universidad del Azuay; 2013.

[36] Tinoco-Alvear M. Estudio de la presencia de aflatoxinas en cereales para niños expendidos al granel en mercados de la ciudad de Cuenca. Cuenca: Universidad del Azuay; 2013.
[37] Bonilla-Jaramillo A. Análisis de ocratoxina en chocolate de hoja comercializado en los mercados de la ciudad de Cuenca. Cuenca: Universidad del Azuay; 2013.

[38] Rojas-Pesántez J. Estudio Preliminar de Aerobios Mesófilos en la leche cruda que se expende en carros repartidores en la ciudad de Cuenca. Cuenca: Universidad del Azuay; 2013.

[39] Bacuilima-Gutiérrez G, Guarango-Guarango J. Calidad bromatológica y microbiológica del dulce de leche sin registro sanitario en cinco puestos de expendio de manera ambulante en el mercado feria libre de la ciudad de Cuenca. Cuenca: Universidad de Cuenca; 2013.

[40] Vélez-Bravo A, Ortega-González J. Determinación de coliformes totales y E. Coli en muestras de lechuga expendidas en cuatro mercados de la ciudad de Cuenca. Cuenca: Universidad de Cuenca; 2013.

[41] Patiño-Bernal N, Vázquez-Mendoza V. Determinación de la concentración de nitritos en salchicha tipo Frankfurt que se comercializa en los mercados de la ciudad de Cuenca. Cuenca: Universidad de Cuenca; 2013.

[42] Becerra-Delgado J. Determinación de metales en cerveza. Cuenca: Universidad del Azuay; 2014.

[43] Loja-Alulema C, Sanmartín-Sagbay L. Evaluación de la calidad microbiológica del chocho desamargado para el consumo en la ciudad de Cuenca. Cuenca: Universidad de Cuenca; 2014.

[44] Ruiz-Ramón J. Determinación de Salmonella spp. en mayonesa preparada en pollerías ubicadas en el centro histórico de Cuenca. Cuenca: Universidad del Azuay; 2014.

[45] García-Quito M. Determinación de listeria monocytogenes en queso fresco expendido al granel en los mercados de Cuenca. Cuenca: Universidad del Azuay; 2014.

[46] Alejandro-Becerra M. Investigación de microorganismos patógenos en Salchicha tipo Frankfurt que se expenden en el mercado EL ARENAL de la ciudad de Cuenca. Cuenca: Universidad del Azuay; 2015.

[47] Soto-Villegas D. Presencia de Escherichia coli y Staphylococcus aureus en la oferta de alimentos de locales informales de comida rápida ubicados en la avenida de Las Américas de la ciudad de Cuenca. Cuenca: Universidad del Azuay; 2015.

[48] Moreno-Yanes S. Estudio de la presencia de Campylobacter spp. en carcasas de pollos frescos, 
provenientes de los mercados "El Arenal" y "10 de Agosto". Cuenca: Universidad del Azuay; 2015.

[49] Malla-Bravo A, Saula-López S. Determinación del metabolito tóxico aflatoxina $\mathrm{M}_{1}$ en leches cruda, pasteurizada y ultrapasteurizada consumidas en la ciudad de Cuenca mediante la técnica de cromatografía líquida de alta resolución (HPLC). Cuenca: Universidad de Cuenca; 2016.

[50] Tacuri-Campoverde J. Evaluación de la calidad microbiológica de cuyes faenados expendidos en la ciudad de Cuenca. Cuenca: Universidad del Azuay; 2016.

[51] Sánchez-Torres C. Análisis parasitológico de la frutilla cultivada en la parroquia San Joaquín, y expendida en la ciudad de Cuenca. Cuenca: Universidad el Azuay; 2016.

[52] Sempértegui-Puente M. Evaluación de la calidad microbiológica de las ensaladas frescas vendidas en dos mercados de la ciudad de Cuenca y su asociación con los factores de riesgo para adquirir enfermedades transmitidas por los alimentos. Cuenca: Universidad del Azuay; 2016.

[53] Vallejos-Quisigüiña G. Determinación de Aflatoxina $M_{1}$ en quesillos artesanales comercializados en los mercados de la ciudad de Cuenca mediante la técnica de cromatografía líquida de alta resolución (HPLC). Cuenca: Universidad de Cuenca; 2016.

[54] Arciniega-Alvarado G. Determinación de Histamina por el método de ELISA en pescado fresco comercializado en el mercado municipal "EL ARENAL" de la ciudad de Cuenca. Cuenca: Universidad del Azuay; 2016.

[55] Andrade-Serrano S. Análisis y evaluación del riesgo microbiológico de Clostridium perfringens en hornado del mercado 10 de agosto. Cuenca: Universidad del Azuay; 2017.

[56] Ortiz M. et al. Estudio exploratorio sobre la presencia de contaminantes en leche cruda proveniente de la cuenca lechera del Tarqui de la Sierra Sur Ecuatoriana. Maskana. 2017; 8:121-127.

[57] Ochoa-Coronel E. Determinación de Staphylococcus aureus en las mayonesas de los locales de expendio de alimentos en el Terminal Terrestre de Cuenca. Cuenca: Universidad del Azuay; 2017.

[58] Sánchez-Astudillo A. Determinación de la concentración de plomo y arsénico presente en el tejido blando del cangrejo que se expende en el mercado El Arenal de la ciudad de Cuenca. Cuenca: Universidad del Azuay; 2017.
[59] Olea A. et al. Vigilancia de brotes de enfermedades transmitidas por alimentos en Chile. Rev Chil Infectol. 2012; 29(12):504-510.

[60] Mercado M. et al. Brotes por Salmonella spp., Staphylococcus aureus y Listeria monocytogenes asociados al consumo de pollo. Biomédica. 2012; 32(3):375-385.

[61] Galvis E. Revisión sistemática descriptiva sobre la presencia de Listeria monocytogenes en brócoli (Brassica oleracea var italica) y coliflor (Brassica oleracea var botrytis). Bogotá: Universidad de la Salle; 2016.

[62] Gimate S. Análisis basado en la evidencia de seguridad alimentaria: PESA-Oaxaca, México. Rev Cienc Soc. 2016; 4(154):129-148. 